\title{
Impact assessment of change in anthropogenic emissions due to lockdown on aerosol characteristics in a rural location
}

\author{
A. Ajay ${ }^{1,2, *}$, K. Krishna Moorthy ${ }^{3}$, S. K. Satheesh ${ }^{2,3}$ and G. Ilavazhagan ${ }^{1}$ \\ ${ }^{1}$ Hindustan Institute of Technology and Science, Chennai 603 103, India \\ ${ }^{2}$ Divecha Centre for Climate Change, Indian Institute of Science, Bengaluru 560 012, India \\ ${ }^{3}$ Centre for Atmospheric and Oceanic Sciences, Indian Institute of Science, Bengaluru 560 012, India
}

\begin{abstract}
Long-term and continuous measurements of aerosol concentration and optical properties from the Challakere Climate Observatory, located in a remote rural semi-arid region northwest of Bengaluru, are examined for the impact of the prolonged and phased national lockdown during the COVID-19 pandemic. The analyses revealed that the lockdown, which almost brought all the anthropogenic activities (particularly associated with fossil fuel use such as in transport and industrial sectors) to a standstill and then slowly relaxed in phases, had very little impact on the aerosol properties at this remote site, in sharp contrast to the impacts seen in the major urban conglomerate, Bengaluru, located about $230 \mathrm{~km}$ southeast to Challakere. Rather than impacts from anthropogenic sources associated with fossil fuel combustion, the aerosol characteristics at Challakere are strongly influenced by regional and synoptic meteorology. The findings re-emphasize that the emissions from fossil fuel combustion in industrial and automobile sector are the major source of aerosols (especially absorbing type) over urban and semi-urban environments.
\end{abstract}

Keywords: Anthropogenic emissions, black carbon, COVID-19 lockdown, rural aerosols, scattering coefficients, single scattering albedo.

\section{Introduction}

THE role of emissions (anthropogenic/natural) of combustion products leading to sudden perturbation in the concentration and other properties of lower atmospheric aerosols and trace gases has been well documented ${ }^{1,2}$. Several case studies of pollution due to forest fire, oil well fire and festivals like Diwali have shown 2 to 6 fold increase in pollution levels for a short period ${ }^{3-7}$. Similarly, sudden cessation of human activities has also shown to impact the environment ${ }^{8-10}$. However, almost all these remained isolated case studies, mostly based on very short-term events or a point source of perturbation. In

*For correspondence. (e-mail: ajay1@iisc.ac.in) contrast, the national lockdown (LD) associated with the COVID-19 pandemic provided a unique event, where the human activities (in industrial, transport, commercial and energy sectors) were completely shut down over the entire Indian region for a fairly long period and thereafter relaxed in a phased manner, thereby providing an opportunity to assess how the environment responds to manmade perturbations. This article reports the impacts of these on aerosol properties over a remote rural location Challakere $\left(14.41^{\circ} \mathrm{N}, 76.56^{\circ} \mathrm{E}\right.$ and $600 \mathrm{~m}$ amsl), located about $230 \mathrm{~km}$ northwest of the megacity Bengaluru, based on continuous and long-term measurements.

\section{Lockdown phases}

The COVID-19 LD, initiated on 24 March 2020, with large relaxations implemented in phases, is well publicized. A short account of the sequence of events is explained in brief.

- LD1 (March 24 to April 14): Total shutdown in people movements 'Stay at home approach', complete cessation of vehicular traffic (road, rail, air and water traffic) except emergency services. Industries, commercial establishments, places for entertainment, place of worship and educational institutions remained closed. Public gatherings banned. Large reduction in energy use.

- LD2 (April 15 to May 03): Restrictions on transport sector relaxed permitting movement of essential goods and emergency services. Complete restrictions confine to areas identified with infections. Industries, commercial establishments, places of worship and educational institutions continued to be closed, except for small scale establishments.

- LD3 (May 04 to May 17): Although large industries, commercial establishments, places of worship and educational institutions continued to be closed, more relaxation were allowed in transport section, and restricted functioning of government offices and private establishments. Limited-scale restoration of air and rail traffic. 


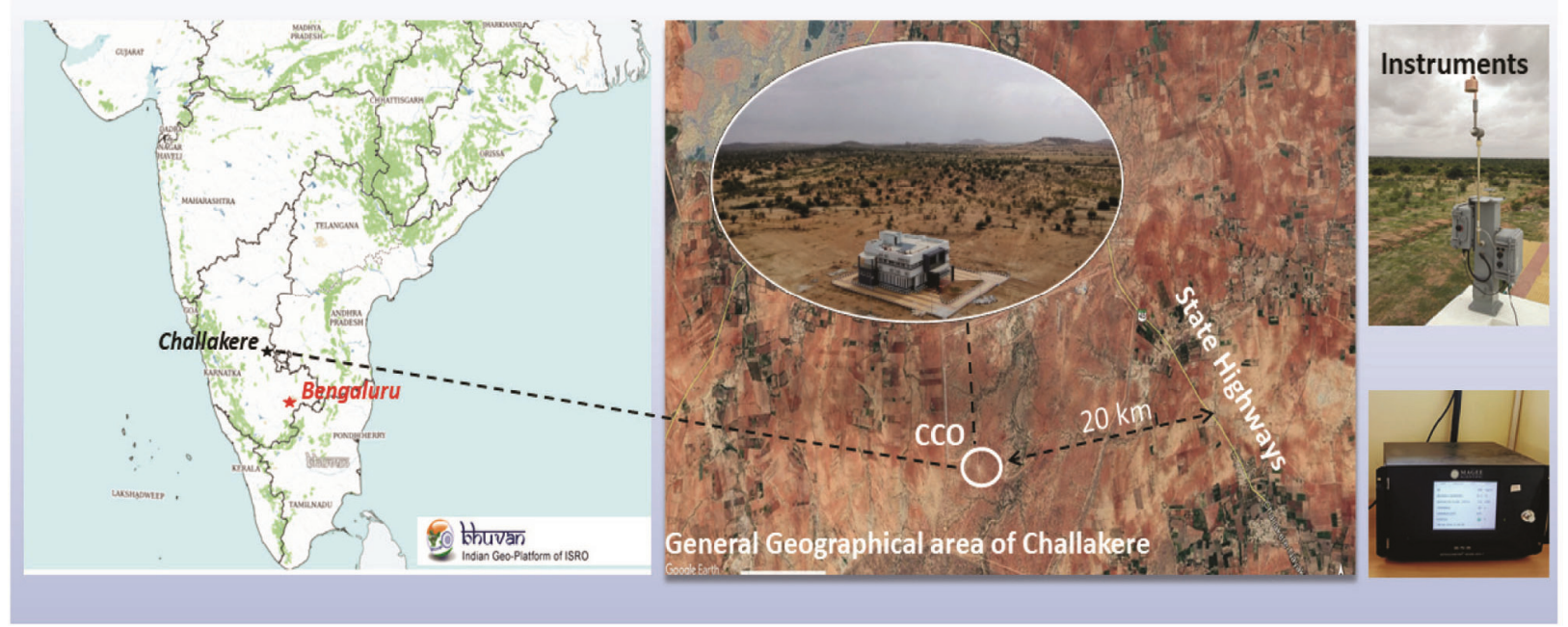

Figure 1. Geographical location of the measurement site Challakere ( $\star$ symbol) IISc second campus and Bengaluru ( $\star$ symbol) main campus along with aerial terrain-satellite view of Challakere Climate Observatory (white circle) and local Geographical area of Challakere.

- LD4 (May 18 to May 31): More relaxation in traffic and small business establishments with night-time restrictions from 21:00 PM to 05:00 AM; large industries, commercial establishments places for public entertainment and educational institutions continued to be closed, and large gatherings continued to be restricted.

- Unlock (UL1) (June 01 to June 30): Transition from LD to unlock in a phased manner. More relaxation in road, rail and domestic air traffic. Major industries resumed with stringent safety measures and places of worship opened to public with strict guidelines.

- UL2 (from July 01): Further relaxations from UL1 conditions, while restrictions continued with respect to functioning of educational institutions, large commercial activities, cinema halls, large social and political gatherings and international air travel except of repatriation.

\section{Sampling location, measurements and data}

The experimental data used in this study are obtained from the Challakere Climate Observatory (CCO, $14.41^{\circ} \mathrm{N}, 76.56^{\circ} \mathrm{E}, 600 \mathrm{~m}$ amsl) located well inside the vast second campus of the Indian Institute of Science (IISc) at Challakere (CHK) in Chitradurga district of northern Karnataka; about $230 \mathrm{~km}$ northwest of Bengaluru (Figure 1). The general geography of CHK comprises a flat semi-arid terrain. It is a village with an area of $31 \mathrm{~km}^{2}$ in the Chitradurga district $\left(7700 \mathrm{~km}^{2}\right)$. The CCO along with its background is also shown in Figure 1. It is located about $10 \mathrm{~km}$ away from the village centre and $20 \mathrm{~km}$ away from the state highway with no conspicuous human activities in the near vicinity. Though there are a few industries in Chitradurga district, they are located
$>30 \mathrm{~km}$ away from CHK. The campuses of IISc and other institutions such as DRDO, ISRO and BARC occupy a major part of CHK.

Continuous measurements of black carbon (BC) and scattering coefficients of composite aerosols (both near the surface) are being made from CCO (since 2015 for $\mathrm{BC}$ and 2018 for scattering coefficients) using dedicated online instruments, which aspire the ambient air from a height of $\sim 10 \mathrm{~m}$ above ground level. An Aethalometer ${ }^{11-13}$ (AE-33 of Magee Scientific) is used to measure near-realtime $\mathrm{BC}$ mass concentration at one-minute interval. The instrument uses dual spot technology and measures attenuation of light at 7 different wavelengths (370, 470, 520, $590,660,880$ and $950 \mathrm{~nm}$ ), passing through a quartz filter tape, on which the aerosol particles are deposited. The mass concentration is estimated from the incremental attenuation at $880 \mathrm{~nm}$ between two successive measurements using the specific mass absorption cross section (MAC) of BC. More details are available in the literature $^{14-16}$. The measurements are corrected for filter loading $^{17}$ and multiple scattering ${ }^{18}$. The instrument also provides the concentration of the major constituents of $\mathrm{BC}$ in terms of their origin; biomass $\left(\mathrm{BC}_{\mathrm{wb}}\right)$ and fossil fuel $\left(\mathrm{BC}_{\mathrm{ff}}\right)^{15}$. The concentrations are calculated from the percentages as follows.

$$
\begin{aligned}
& \mathrm{BC}_{\mathrm{wb}}=\mathrm{BB} \times \mathrm{BC} . \\
& \mathrm{BC}_{\mathrm{ff}}=\mathrm{BC}-\mathrm{BC}_{\mathrm{wb}} .
\end{aligned}
$$

Total and back scattering coefficients of composite PM10 aerosols are measured continuously using a 3-wavelength $(450,532,632 \mathrm{~nm})$ integrating nephelometer ${ }^{19}$ (IN102 from AirPhoton) fitted with a cyclone inlet. The measurements are made over an angular range $7^{\circ}$ to $170^{\circ}$ and 
uses the in-built CR100 clean air reference system for zero calibration, which is done every 15 minutes automatically. The nephelometer measurements suffer from truncation and angular nonidealities errors, which depend on particle size. These are corrected following Anderson ${ }^{20}$ using Mie theory modelling ${ }^{21}$. These data until May 2020 are used for this study.

\section{General meteorological conditions}

The prevailing meteorological conditions at Challakere are typical to the tropical climate experienced by the peninsular region; being classified into four seasons Winter - December, January and February, summer March, April and May, monsoon - June, July, August and September and post-monsoon-October and November. Low easterly/north-easterly winds prevail during winter and early spring, changing over to strong westerlies during monsoon and reverting through post-monsoon season $^{22}$. Being a semi-arid region in the Deccan Plateau, Chitradurga in general, and $\mathrm{CHK}$, in particular, receives low to very low rainfall with strong annual variations as shown in Figure 2.

\section{Results and discussions}

In the following we assess the impact of LD on different aerosol properties by examining their time-series. As the LD extended over a long duration with phased relaxations in-between, it is likely that significant 'secular variations' which occur with change in season and the associated changes in synoptic meteorology would be impacting the properties of aerosols. As such, it is essential to examine the climatological features before trying to delineate the impact of the lockdown.

\section{Black carbon aerosols}

As we had separated the different components of BC (from fossil fuel and biomass burning) from the Aethalometer data, the impact assessment was carried out separately for these two species. In Figure $3 a$, the temporal variations of the climatological mean daily concentrations of $\mathrm{BC}_{\mathrm{ff}}\left(\mathrm{BC}_{\mathrm{ff}-\mathrm{ref}}\right)$, obtained by averaging daily data for the period 2015 through 2019 (excluding 2020), are shown for the period January to May by the black line joining the black spheres. Here the spheres represent the climatological daily mean values of $\mathrm{BC}_{\mathrm{ff}}$ and the line represents 5 -point running smoothed variations. The vertical lines through the points represent the standard deviations of the mean (standard error). This serves as a reference or control data against the variation of the daily mean values of $\mathrm{BC}_{\mathrm{ff}}$ for the same period of 2020 are compared. These are shown by the red line through the red spheres where the spheres and line have the same meaning as for the black coloured ones.

To examine the deviation of the year 2020 from the control/reference pattern for $\mathrm{CHK}$, we have estimated the difference $\Delta_{\mathrm{BC}_{\mathrm{ff}}}$ between the reference values and the corresponding values for 2020 and their standard errors $\varepsilon_{\text {diff }}$ as

$$
\begin{gathered}
\Delta_{\mathrm{BC}_{\mathrm{ff}}}=\mathrm{BC}_{\mathrm{ff}-\mathrm{ref}}-\mathrm{BC}_{\mathrm{ff}-2020}, \\
\varepsilon_{\mathrm{diff}}=\sqrt{\frac{\varepsilon_{1}^{2} N_{1}+\varepsilon_{2}^{2} N_{2}}{N_{1}+N_{2}}},
\end{gathered}
$$

where $\varepsilon_{1}$ and $\varepsilon_{2}$ are the standard errors of the daily mean concentration of $\left(\mathrm{BC}_{\mathrm{ff-ref}}\right)$ and $\left(\mathrm{BC}_{\mathrm{ff}-2020}\right)$ respectively. $N_{1}$ and $N_{2}$ are the number of data points. The time series of the daily mean values of $\Delta_{\mathrm{BC}_{\mathrm{ff}}}$ is shown in Figure $3 b$ along with the 5-point running mean smoothed curve. The figure reveals the following:

- In general, $\mathrm{BC}_{\mathrm{ff}}$ executes a 'secular variation' starting from a moderately high value in January (when $\mathrm{BC}_{\mathrm{ff}-\mathrm{ref}}$ stays around $1.73 \mu \mathrm{g} \mathrm{m}^{-3}$ ) and start decreasing steadily from mid-February to reach low values of $\sim 0.8 \mu \mathrm{g} \mathrm{m}^{-3}$ by end of May.

- In 2020 also, the variations are much similar to the above pattern, as seen from the red line; however, there are some conspicuous perturbations during the LD, especially during LD1.

- These changes are shown clearly in Figure $3 \mathrm{~b}$. A small, yet definite, positive peak, showing a small reduction in the fossil fuel related $\mathrm{BC}$, occurs during the LD1 phase and just prior to it when there were local restrictions imposed on general road traffic since March 15. However, these subsided by the end of LD1 phase and from LD2 onwards the difference from the control data is not significant at all.

- Summarily, the effect of LD was negligible in CHK and whatever little observed was confined only to the

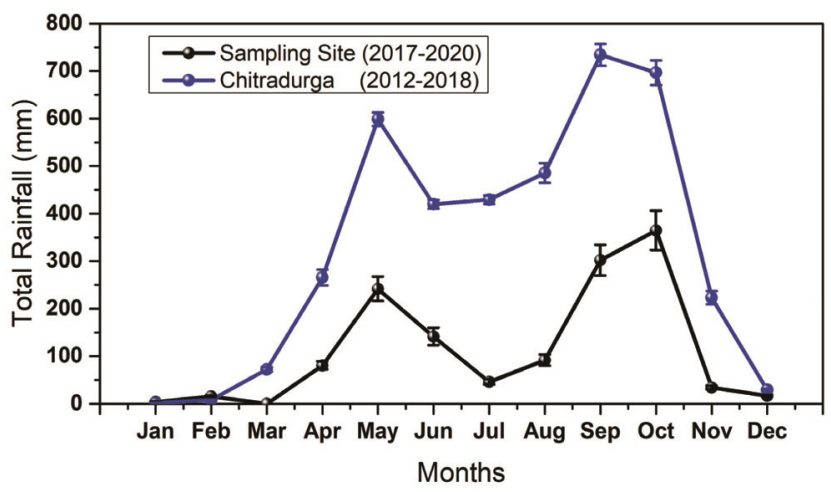

Figure 2. Climatological monthly total rainfall for Chitradurga district (from India Meteorological Department: 2012 to 2018) and at the CCO using rain gauge (2017-2020). 

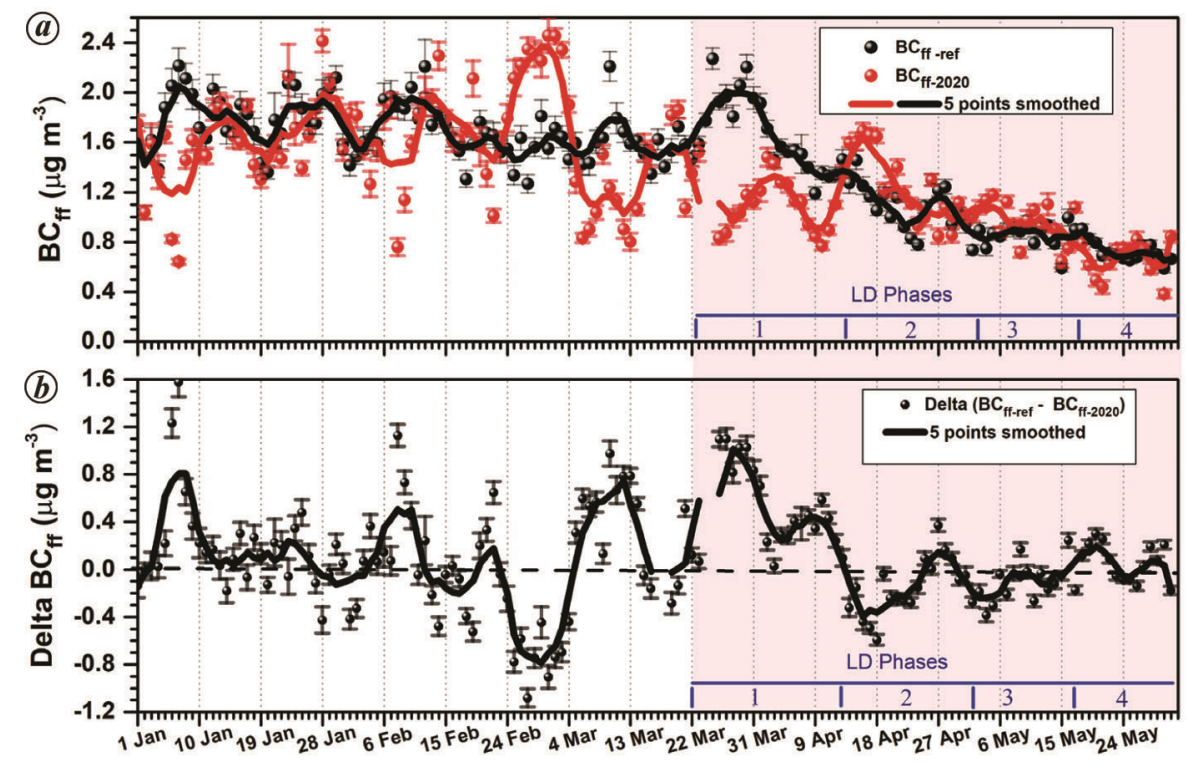

\section{Date}

Figure 3. Daily temporal variations of $\mathrm{BC}_{\text {ff-ref }}$ (black colour) and $\mathrm{BC}_{\mathrm{ff}-2020}$ (red colour) starting from 1 January to 31 May $(\boldsymbol{a})$ and $(\boldsymbol{b})$ shows difference of $\mathrm{BC}_{\mathrm{ff}}$ from reference climatology and present daily mean. Light shaded vertical lines represent standard error.
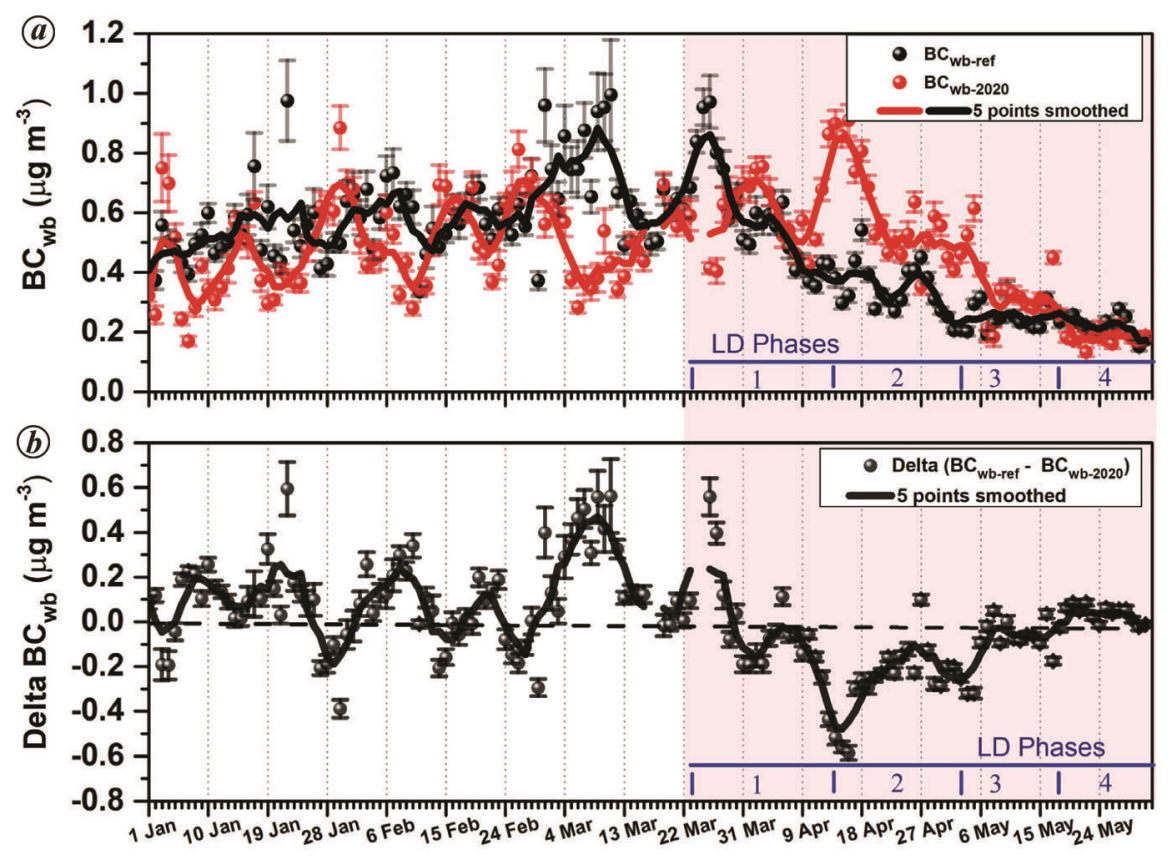

Date

Figure 4. Daily temporal variations of $\mathrm{BC}_{\mathrm{wb}-\text { ref }}$ (black colour) and $\mathrm{BC}_{\mathrm{wb}-2020}$ (red colour) starting from 1 January to 31 May $(\boldsymbol{a})$ and $(\boldsymbol{b})$ shows difference of $\mathrm{BC}_{\mathrm{wb}}$ from reference climatology and present daily mean. Light shaded vertical lines represent standard error.

LD1 phase. This is in sharp contrast to what was seen in the urban region Bengaluru (where a $60 \%$ decrease in $\mathrm{BC}_{\mathrm{ff}}$ concentration is noted $\left.{ }^{23}\right)$.

The biomass burning component of $\mathrm{BC}\left(\mathrm{BC}_{\mathrm{wb}}\right)$ did not show any perceptible impact of the lockdown in any of its phases as seen from Figure 4; where the time series for the reference period and 2020 are shown in Figure $4 b$ and the decrease in 2020 with respect to Figure $4 b$, following the same conventions as in Figure 3. A minor increase in concentration seen during the LD2 phase has been attributed to isolated burning of litter and dry 


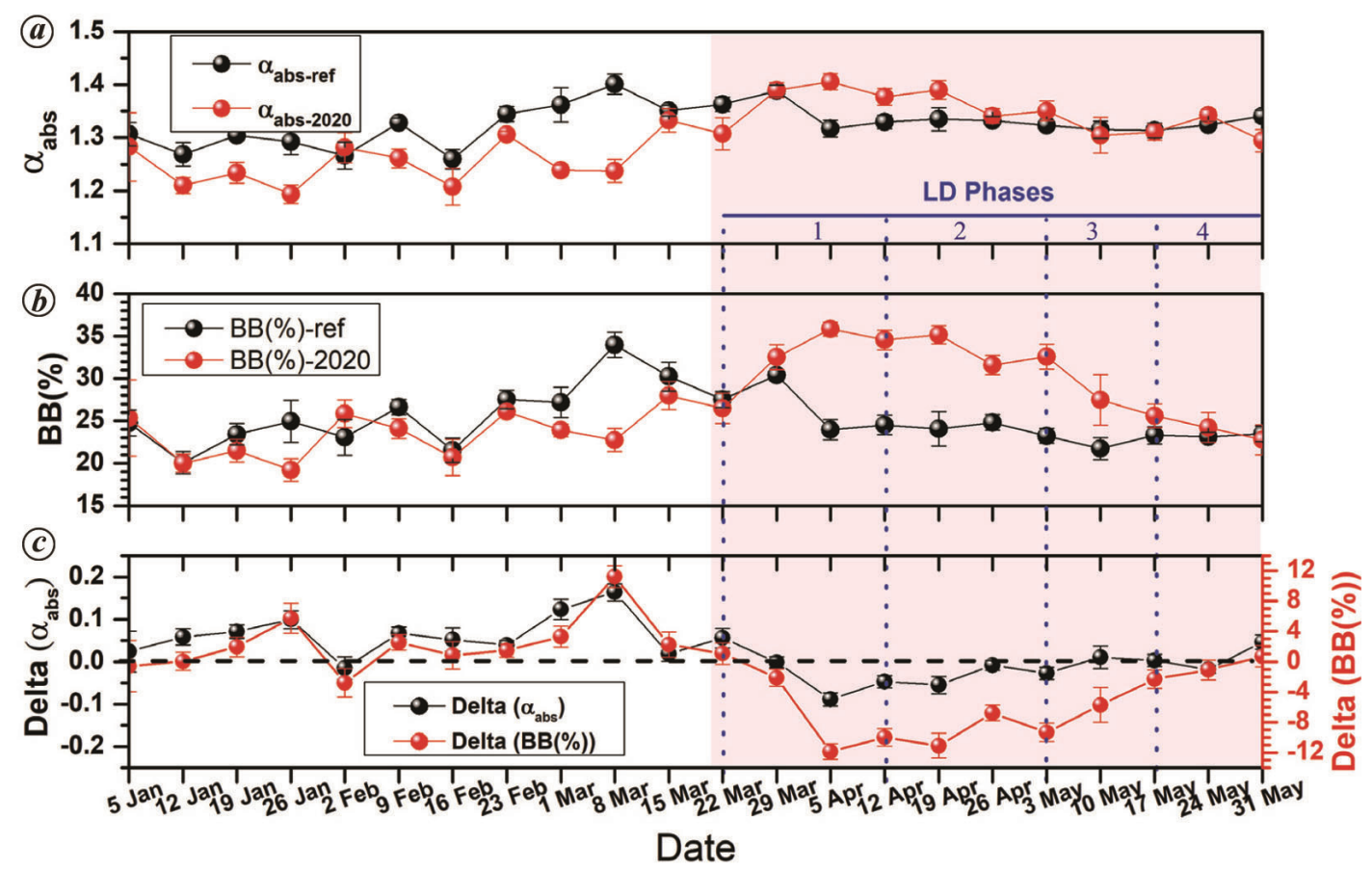

Figure 5. Weekly variations of absorption Angstrom exponent (a) and BB (\%) (b) for reference (black colour) and 2020 (red colour). $c$, shows difference of reference and 2020.

vegetation in the vicinity by the local population. Though these activities were sighted by the observers in the station, the exact quantum of burning could not be assessed.

Summarily, Figures 3 and 4 together show that there was no perceptible impact of the lockdown on the $\mathrm{BC}$ concentration at $\mathrm{CHK}$, except for a small decrease in the fossil fuel linked $\mathrm{BC}$ during the total lockdown phase (LD1) due to complete stopping of vehicular traffic. Rather, the temporal variations at this location are more controlled by the local meteorology as seen for the control period.

\section{BC spectral absorption characteristics}

To understand how the above changes impacted the spectral absorption properties of $\mathrm{BC}$, if any, we estimated the absorption Angstrom exponent by evolving a least squares fit in a log-log scale to spectral absorption coefficient $\left(\beta_{\mathrm{abs}}\right)$ estimated from the Aethalometer measurements for the 7 wavelengths (370 to $950 \mathrm{~nm})$ to the Angstrom relation

$$
\beta_{\mathrm{abs}}(\lambda)=\lambda^{-\alpha_{\mathrm{abs}}}
$$

where $\alpha_{\mathrm{abs}}$ is the Absorption Angstrom exponent. Kirchstetter et al. ${ }^{14}$ have shown that $\alpha_{\text {abs }}$ value close to 2 shows strong influence of emissions from biomass burning to the total $\mathrm{BC}$, while $\alpha_{\mathrm{abs}}$ close to 1 indicates near total dominance of fresh diesel emissions.
Figure $5 a$ and $b$ shows the weekly averaged values $\alpha_{\mathrm{abs}}$ and the biomass percentage share of burning component to total BC (BB) for reference (black colour) and 2020 (red colour). It shows the following:

- In general, $\alpha_{\mathrm{abs}}$ remains above 1.2 at $\mathrm{CHK}$, implying mixed BC with strong signatures of biomass burning/ aged fossil fuel BC.

- From 14 March, when the local activities were restricted prior to the LD1 phase, $\alpha_{\text {abs }}$ started increasing (showing decreasing $\mathrm{BC}_{\mathrm{ff}}$ /increasing share of $\mathrm{BB}$ ) and reached the peak value of $\sim 1.4$ during the LD1 phase when $\mathrm{BB}(\%)$ also reached the peak of $\sim 35 \%$.

- During the subsequent weeks, $\alpha_{\mathrm{abs}}$ decreased gradually as $\mathrm{BB}(\%)$ also decreased consequent to the relaxation in LD and increase in vehicular traffic.

- Figure $5 c$ shows difference of $\alpha_{\mathrm{abs}}$ and $\mathrm{BB}(\%)$ from reference and 2020 observations calculated using equations (3) and (4) which shows that differences are close to zero apart from small variations.

\section{Scattering properties of composite aerosols}

Total and back scattering coefficients $\left(\beta_{\mathrm{st}}\right.$ and $\left.\beta_{\mathrm{sb}}\right)$ measured by the nephelometer at 450, 532 and $632 \mathrm{~nm}$ are interpolated/extrapolated to 450,550 and $700 \mathrm{~nm}$ wavelengths (for estimating the single scattering albedo by combining them with the absorption data) using the wavelength dependence deduced from the same data and 

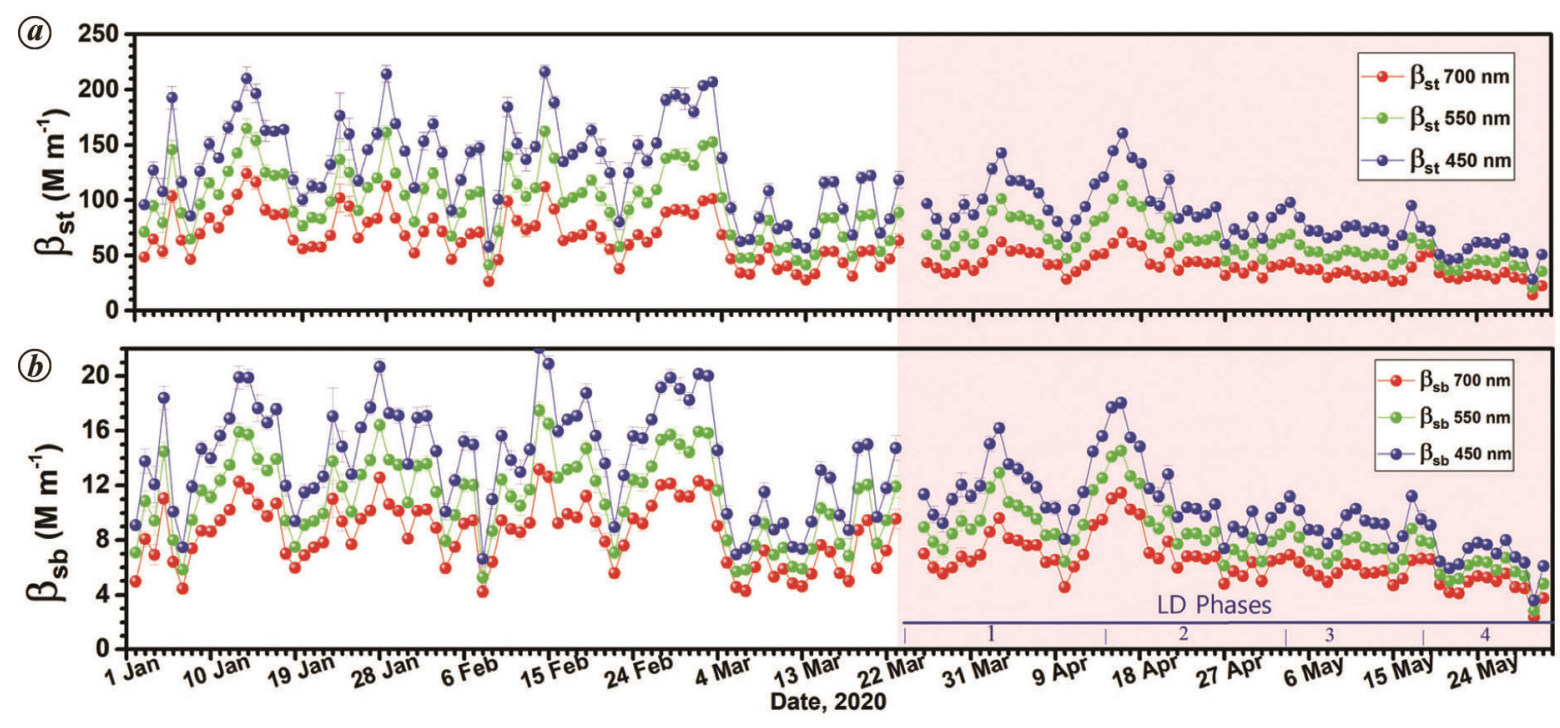

Figure 6. Daily temporal variations of total scattering ( $\beta_{\mathrm{st}}$ in $\left.\boldsymbol{a}\right)$ and back scattering $\left(\beta_{\mathrm{sb}}\right.$ in $\left.\boldsymbol{b}\right)$ at three wavelengths. Vertical lines along the dots represent standard error.

the variations of these are shown in Figure 6. The important features in the figure are:

(1) The sudden reduction in the magnitude of scattering coefficients from the pre-LD period during the advent of summer due to meteorological conditions and impact of lockdown is negligible.

(2) Daily variations of scattering coefficients show high values in winter season and with advent of summer concentration drastically reduced due to prevailing meteorological conditions.

(3) Scattering coefficients values for the control period are more or less the same as those reported by Anand $^{22}$ for the normal period and show very little changes due to lockdown.

(4) Apart from day to day fluctuations, scattering coefficients continue to decrease further similar to absorbing aerosols starting from summer season till end of May during different lockdown phases, which is due to large reduction in aerosols source strength associated with seasonal changes.

Due to reduction in anthropogenic pollution, size spectrum of aerosols undergoes changes which is examined by plotting the Angstrom exponent due to scattering aerosols $\alpha_{\text {sca }}$ (which is calculated using eq. (6) from wavelength 450 to $700 \mathrm{~nm}$ by plotting $\beta_{\text {sca }}$ in a regression line using a $\log -\log$ scale). Figure 7 shows weekly variations of $\alpha_{\mathrm{sca}}(\boldsymbol{a})$ and back scatter fraction $\left(b=\beta_{\mathrm{sb}} / \beta_{\mathrm{st}}\right)(\boldsymbol{b})$ for reference (black) and 2020 (red). Both these show an increasing trend for the entire study period with weekly fluctuations due to different source strengths. $\alpha_{\text {sca }}$ saw a marginal increase from 1.6 to 1.8 from winter to summer, implying dominance of sub-micron sized particles and did not witness any significant changes during the LD phases.

$$
\beta_{\mathrm{sca}}(\lambda) \propto \lambda^{-\alpha_{\mathrm{sca}}} .
$$

An interesting observation is that $\alpha_{\text {sca }}$ reduced up to $\sim 60 \%$ on third week of May, owing to extensive rainfall received during this period ${ }^{23}$.

Backscatter ratio, an indicator of fine mode aerosols, varies in line with $\alpha_{\text {sca }}$ which further substantiates the reduction in coarse mode particles. From general Mie theory of light scattering with different shapes, it is clear that increase in back-scatter ratio is indicative of increase in finer mode particles. Figure 7 reveals that the shift in size spectrum from fine mode to accumulation mode is mainly due to seasonal changes and effect of LD is negligible, extensive rainfall is the main reason for significant reduction in the effective radius.

\section{Intensive properties of aerosols}

Radiative forcing of aerosols depends on several important parameters such as single scattering Albedo (SSA) and asymmetry parameters $(g)$, which contribute significantly to forcing ${ }^{24}$. SSA is estimated from simultaneous measurements of scattering and absorption aerosols by the following equation

$$
\operatorname{SSA}(\lambda)=\frac{\beta_{\mathrm{st}}(\lambda)}{\beta_{\mathrm{st}}(\lambda)+\sigma_{\mathrm{abs}}(\lambda)},
$$

where $\beta_{\mathrm{st}}$ and $\sigma_{\mathrm{abs}}$ are total scattering and absorption coefficient calculated for wavelength $550 \mathrm{~nm}$. Magnitude of 


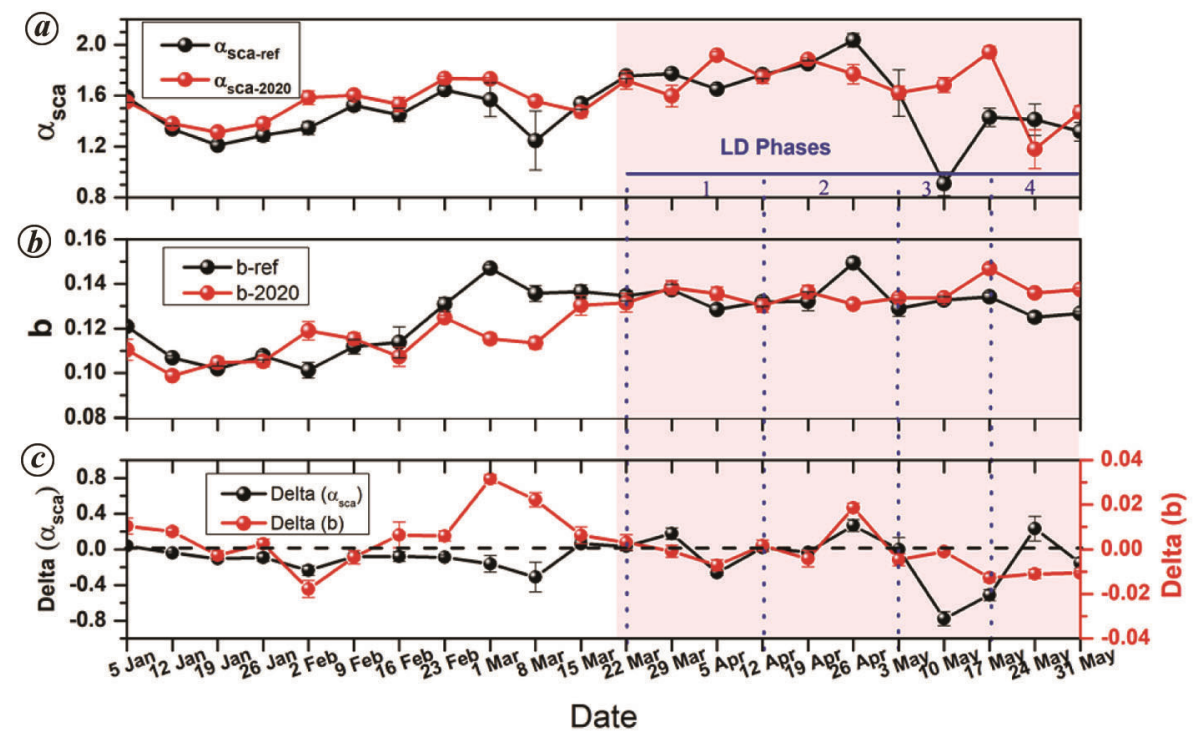

Figure 7. Weekly variations of scattering Angstrom exponent (a) and back scatter ratio (b) for reference (black colour) and 2020 (red colour). $c$, shows difference of reference and 2020.

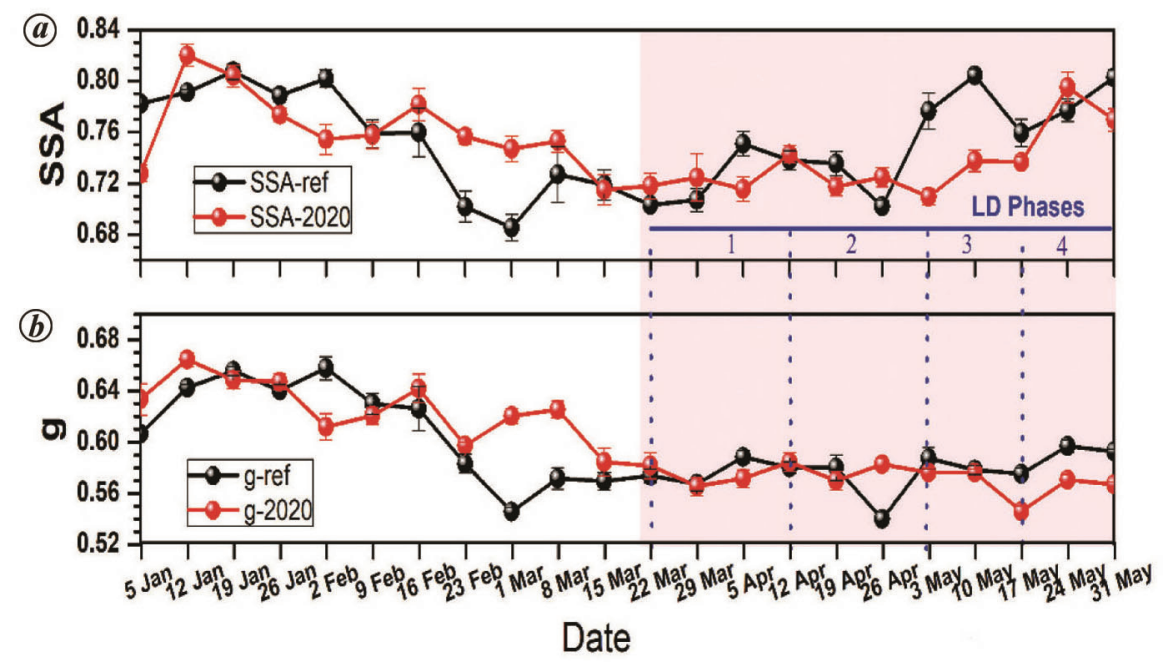

Figure 8. Weekly variations of Single Scattering Albedo (a) and asymmetry parameter (b) at $550 \mathrm{~nm}$ wavelength for reference (black colour) and 2020 (red colour).

SSA can be considered as index of relative type of scattering and absorbing aerosols whose values range from 0 (purely absorbing) to 1 (purely scattering). It can be seen from Figure $8 a$ that SSA did not show any preeminent changes due to lockdown phases and maintained its level with mean value of 0.72 until the beginning of LD4 phase where SSA saw sudden jump from 0.72 to 0.8 , this unprecedented rise is due to high precipitation.

Asymmetry parameter $(g)$, which is defined as cosineweighted average of the phase function and representation of angular scattering properties, is calculated (Figure $8 \mathrm{~b}$ ) from the following equation using nephelometer scattering coefficient Wiscombe and Grams ${ }^{25}$; Andrews ${ }^{26}$. It depends on size and composition of the particles. The value of $g$ ranges between -1 for entirely back scattered light and to +1 for forward scattered light. There is a continuous decreasing trend observed starting from first week to last week of May which is mainly due to increase in spectral dependence of scattering coefficients which correspond to decrease in fine mode particles associated with seasonal changes.

$$
g=-7.143 \times b^{3}+7.464 \times b^{2}-3.963 \times b+0.9893 .
$$

Table 1 lists some of the important parameters at both these locations during different phases of the lockdown. The values for Bengaluru are taken from Ajay et al. (this issue). It is interesting to note that while Bengaluru 
Table 1. Comparison of lockdown effects of aerosol parameters at Challakere (CHK) and Bengaluru (BLR)

\begin{tabular}{|c|c|c|c|c|c|c|c|c|}
\hline \multirow[b]{2}{*}{ Period } & \multicolumn{2}{|c|}{$\mathrm{BC}_{\mathrm{ff}}\left(\mu \mathrm{g} \mathrm{m}^{-3}\right)$} & \multicolumn{2}{|c|}{$\beta_{\mathrm{st}}\left(\mathrm{M} \mathrm{m}^{-1}\right)$} & \multicolumn{2}{|c|}{$\alpha_{\text {sca }}$} & \multicolumn{2}{|c|}{ Single Scattering Albedo } \\
\hline & CHK & $\mathrm{BLR}^{\#}$ & CHK & BLR & $\mathrm{CHK}$ & BLR & CHK & BLR \\
\hline Pre-LD (6 March to 23 March) & $1.25 \pm 0.09$ & $4.33 \pm 0.15$ & $64 \pm 4$ & $130 \pm 4$ & $1.55 \pm 0.05$ & $1.49 \pm 0.02$ & $0.717 \pm 0.007$ & $0.66 \pm 0.01$ \\
\hline LD1 (24 March to 14 April) & $1.12 \pm 0.05$ & $1.69 \pm 0.04$ & $71 \pm 3$ & $107 \pm 8$ & $1.83 \pm 0.03$ & $1.81 \pm 0.03$ & $0.726 \pm 0.007$ & $0.74 \pm 0.005$ \\
\hline LD2 (15 April to 3 May) & $1.21 \pm 0.06$ & $2.23 \pm 0.12$ & $70 \pm 4$ & $90 \pm 5$ & $1.74 \pm 0.04$ & $1.84 \pm 0.02$ & $0.721 \pm 0.004$ & $0.69 \pm 0.011$ \\
\hline LD3 (15 April to 3 May) & $0.96 \pm 0.04$ & $2.58 \pm 0.25$ & $53 \pm 2$ & $82 \pm 7$ & $1.83 \pm 0.05$ & $1.87 \pm 0.04$ & $0.738 \pm 0.005$ & $0.67 \pm 0.010$ \\
\hline LD4 (15 April to 3 May) & $0.66 \pm 0.04$ & $1.88 \pm 0.09$ & $43 \pm 3$ & $61 \pm 3$ & $1.32 \pm 0.08$ & $1.39 \pm 0.10$ & $0.780 \pm 0.009$ & $0.69 \pm 0.012$ \\
\hline
\end{tabular}

"Values for Bengaluru are taken from Ajay et al. (this issue, pp. 287-295).

recorded a $60 \%$ reduction in $\mathrm{BC}$ from fossil fuel emissions and $\mathrm{a}>20 \%$ reduction in total scattering coefficient with associated reduction in SSA and increase in absorption and scattering Angstrom exponents from pre-LD to LD1, CHK remained almost isolated from such large changes; rather the aerosol properties in CHK have been controlled by the changes in the prevailing meteorology. This study clearly establishes that emissions associated with large-scale anthropogenic activities (especially from automobile and urban activities) are chiefly responsible for the deterioration of air quality and increased pollution levels in urban environments. Further, it also emerges that the environment quickly responds to any cessation of such activities, even for periods as short as two weeks, with the environmental parameters over the urban area tending close to those seen over rural areas.

\section{Conclusions}

This study using ground-based measurement data has shown that:

(1) At the rural location Challakere, the impacts of the restrictions imposed by the LD have been very marginal; both on carbonaceous aerosols (from biomass burning and fossil fuel combustion) as well as on composite aerosols, and even these were perceptible only during the complete lockdown phase (LD1).

(2) The optical properties of aerosols, important from the radiative forcing perspective, such as the SSA and asymmetry parameters did not show any impact of the lockdown.

(3) This was in sharp contrast to the pattern seen over the urban region of Bengaluru, located nearby, where the LD produced large impacts in terms of reduction in aerosol loading and increase in SSA.

(4) The site CHK almost retains its rural characteristics reported $^{27}$ way back in 2013.

1. Babu, S. S. and Moorthy, K. K., Anthropogenic impact on aerosol black carbon mass concentration at a tropical coastal station: a case study. Curr. Sci., 2001, 81, 1208-1214.
2. Beegum, S. N. et al., Spatial distribution of aerosol black carbon over India during pre-monsoon season. Atmos. Environ., 2009, 43, 1071-1078.

3. Badarinath, K. V. S. et al., Variations in black carbon aerosol, carbon monoxide and ozone over an urban area of Hyderabad, India, during the forest fire season. Atmos. Res., 2007, 85, 1826.

4. Pathak, B. et al., Firework induced large increase in trace gases and black carbon at Dibrugarh, India. J. Earth Sci. Eng., 2013, 3, 540 .

5. Gogoi, M. M., Bhuyan, P. K. and Krishna Moorthy, K., Possible impact of a major oil-well fire on aerosol optical depth at Dibrugarh. Curr. Sci., 2007, 92, 1047-1049.

6. Yerramsetti, V. S. et al., The impact assessment of Diwali fireworks emissions on the air quality of a tropical urban site, Hyderabad, India, during three consecutive years. Environ. Monitoring Assess., 2013, 185, 7309-7325.

7. Ganguly, N. D. et al., Analysis of a severe air pollution episode in India during Diwali festival - a nationwide approach. Atmósfera, 2019, 32, 225-236.

8. Latha, K. M., Badarinath, K. V. S. and Krishna Moorthy, K., Impact of diesel vehicular emissions on ambient black carbon concentration at an urban location in India. Curr. Sci., 2004, 86, $451-453$.

9. Sharma, A. R., Shailesh, K. K. and Badarinath, K. V. S., Influence of vehicular traffic on urban air quality - a case study of Hyderabad, India. Transp. Environ., 2010, 15, 154-159.

10. Basagaña, X. et al., Effect of public transport strikes on air pollution levels in Barcelona (Spain). Sci. Total Environ., 2018, 610, 1076-1082.

11. Hansen, A. D. A., Rosen, H. and Novakov, T., Real-time measurement of the absorption coefficient of aerosol particles. Appl. Opt., 1982, 21, 3060-3062.

12. Hansen, A. D. A., Rosen, H. and Novakov, T., The aethalometer an instrument for the real-time measurement of optical absorption by aerosol particles. Sci. Total Environ., 1984, 36, 191-196.

13. Bond, T. C., Anderson, T. L. and Campbell, D., Calibration and intercomparison of filter-based measurements of visible light absorption by aerosols. Aerosol Sci. Technol., 1999, 30, 582-600.

14. Kirchstetter, T. W., Novakov, T. and Hobbs, P. V., Evidence that the spectral dependence of light absorption by aerosols is affected by organic carbon. J. Geophys. Res., 2004, 109, D21208.

15. Sandradewi, J. et al., A study of wood burning and traffic aerosols in an Alpine valley using a multi-wavelength Aethalometer. Atmos. Environ., 2008a, 42, 101-112.

16. Sandradewi, J. et al., Using aerosol light absorption measurements for the quantitative determination of wood burning and traffic emission contributions to particulate matter. Environ. Sci. Technol., 2008b, 42, 3316-3323.

17. Drinovec, L. et al., The 'dual-spot' Aethalometer: an improved measurement of aerosol black carbon with real-time loading compensation. Atmos. Meas. Tech., 2015, 8, 1965. 
18. Weingartner, E. et al., Absorption of light by soot particles: determination of the absorption coefficient by means of aethalometers. J. Aerosol Sci., 2003, 34, 1445-1463.

19. Kleidman, R. et al., New capability for in situ measurements of particulate matter using size-selecting Nephelometers as part of the SPARTAN network. AGUFM, 2018, A13I-2558.

20. Anderson, T. L. et al., Performance characteristics of a highsensitivity, three-wavelength, total scatter/backscatter nephelometer. J. Atmos. Oceanic Technol., 1996, 13, 967-986.

21. Anderson, T. L. and Ogren, J. A., Determining aerosol radiative properties using the TSI 3563 integrating nephelometer. Aerosol Sci. Technol., 1998, 29, 57-69.

22. Anand, N. et al., Entanglement of near-surface optical turbulence to atmospheric boundary layer dynamics and particulate concentration: implications for optical wireless communication systems. Appl. Opt., 2020, 59, 1471-1483.

23. Ajay, A., Krishna Moorthy, K., Satheesh, S. K. and Ilavazhagan, G., Impact of lockdown-related reduction in anthropogenic emissions on aerosol characteristics in the megacity, Bengaluru. Curr. Sci., 2021, 120(2), 287-295.
24. Satheesh, S. K., Vinoj, V. and Krishna Moorthy, K., Radiative effects of aerosols at an urban location in southern India: observations versus model. Atmos. Environ., 2010, 44, 5295-5304.

25. Wiscombe, W. J. and Grams, G. W., The backscattered fraction in two-stream approximations. J. Atmos. Sci., 1976, 33, 2440-2451.

26. Andrews, E. et al., Comparison of methods for deriving aerosol asymmetry parameter. J. Geophys. Res., 2006, 111, D05S04.

27. Satheesh, S. K. et al., Unusual aerosol characteristics at Challakere in Karnataka. Curr. Sci., 2013, 104, 615.

ACKNOWLEDGEMENTS. We thank the Aerosol lab project team from Indian Institute of Science Challakere campus for excellent data collection. We gratefully acknowledge Divecha Centre for Climate Change for supporting this work.

doi: $10.18520 /$ cs/v120/i2/332-340 